\title{
Dynamics of productivity and technical efficiency in Russian agriculture
}

\section{Journal Article}

\section{Author(s):}

Bokusheva, Raushan; Hockmann, Heinrich; Kumbhakar, Subal C.

Publication date:

2012-09

Permanent link:

https://doi.org/10.3929/ethz-b-000042752

Rights / license:

In Copyright - Non-Commercial Use Permitted

Originally published in:

European Review of Agricultural Economics 39(4), https://doi.org/10.1093/erae/jbr059 


\title{
Dynamics of productivity and technical efficiency in Russian agriculture
}

\author{
Raushan Bokusheva $^{\dagger} *$, Heinrich Hockmann ${ }^{\S}$ and Subal \\ C. Kumbhakar** \\ ${ }^{\dagger}$ ETH Zürich, Switzerland; ${ }^{\S}$ Leibnitz Institute of Agricultural Development \\ in Central and Eastern Europe, Halle, Germany; ${ }^{* * *}$ State University of \\ New York, Binghamton, USA
}

Received August 2009; final version accepted June 2011

Review coordinated by Thomas Heckelei

\begin{abstract}
This paper analyses regional productivity and technical efficiency development in Russian agriculture. We formulate a regional stochastic frontier model by assuming that producers maximise return to the outlay. We control for regional heterogeneity and endogeneity/simultaneity in input decisions, technical efficiency and technical change by employing a two-step estimation procedure. In the first step, we use the system Generalized Method of Moments approach (system GMM), which gives consistent estimates of the production technology parameters. In the second step, we apply the standard stochastic frontier approach to estimate technical efficiency and its determinants.
\end{abstract}

Keywords: total factor productivity, technical efficiency, Russia, GMM estimation

JEL classification: D24, Q12

\section{Introduction}

Considerable growth has taken place in Russian agriculture over the last decade. ${ }^{1}$ According to the Russian National Statistics Agency agricultural output was increasing, on average, by 4.23 per cent annually during the period from 1999 to 2009 (Rosstat I, 2010). This development might have resulted from contributions of several different factors. The literature refers to an improved macroeconomic stability, an increase in agricultural investment induced by more favourable terms of trade (TOT) for agricultural products in recent years, as well as extremely favourable weather conditions

*Corresponding author: Institute for Environmental Decisions, Sonneggstr. 33, 8092 Zurich, Switzerland. E-mail: bokushev@ethz.ch

1 An exception was the year 2010, when agricultural output declined due to extremely unfavourable weather conditions. This caused excessive fires in many Russian agricultural regions. 
from 1999 to 2009 (Brooks and Gardner, 2004; Liefert, Liefert and Shane, 2009). Finally, the transition process has been accompanied by restructuring and learning processes at the micro level, which might also have positively contributed to these recent trends.

While several studies have been conducted to analyse changes in Russian agriculture during the first decade of the economic transition, recent developments in Russian agriculture remain insufficiently studied. Previous studies on Russian agricultural productivity focused on developments at the oblast level and investigated whether agriculture has moved towards sustainable development (Sotnikov, 1998; Voigt and Uvarovsky, 2001; Osborne and Trueblood, 2006; Voigt, 2006; Voigt and Hockmann, 2008). However, the previous literature provides inconsistent evidence regarding the evolution of Russian agricultural efficiency and productivity during the transition. The inconsistencies may stem from differences among individual data sets, primarily reference periods, as well as among data sources and aggregation levels. At the same time, a rather unstable economic environment in the earlier years of transition may have rendered some dynamics difficult to capture using data for rather short time spans.

Most of these earlier studies employed stochastic frontier analysis (SFA) based on the maximum likelihood (ML) method, but these studies did not control for regional heterogeneity and simultaneity/endogeneity problems. However, recent empirical findings by Bokusheva and Hockmann (2006) suggest the presence of both serious differences in production technologies across Russian regions as well as a possible simultaneity in input decisions, technical change development and technical efficiency. Considering these empirical findings, the estimates of the production technology, technical efficiency and productivity might have been biased in the previous studies.

The objective of this paper is to investigate the development of agricultural productivity in Russia by employing a reasonably long data set and a more appropriate modelling approach. We conduct our analysis on the basis of regional data over the period from 1995 to 2008. The paper applies the return-to-the-outlay model, which presents a more adequate modelling approach in the presence of an endogenous choice of netputs (Kumbhakar, 2011). The model is estimated in two steps. In the first step, we use the system Generalized Method of Moments approach (system GMM) (Blundell and Bond, 1998). The application of system GMM allows us to handle more appropriately regional heterogeneity and potential simultaneity of netput decisions, technical change and technical efficiency. The superiority of this approach is shown by comparing the results obtained with the system GMM estimator and those obtained using the standard stochastic frontier approach. In the second step, we apply the ML-based stochastic frontier model to estimate technical efficiency and its determinants. We distinguish between three potential sources of technical inefficiency; namely, the region's economic and social development, the adjustment costs and the input quality. In addition, we consider how technical efficiency evolved in the course of the transition process. Since we allow regional specifics to 
explain heteroskedasticity in both error terms, i.e. in technical inefficiency and the stochastic noise component, we derive a new formula for computing the marginal effects of variables explaining heteroscedasticity. This formula presents an extension of the approach developed by Wang (2002).

The remainder of this paper is organised as follows. Section 2 describes the development of agricultural production in Russia at the national level and provides a brief review of the literature on the development of technical change and technical efficiency at the regional level. Based on this information, we develop several hypotheses for testing. The estimation methodology is presented in Section 3. Section 4 describes the data employed in the empirical analysis. Research findings are discussed in Section 5, while conclusions are drawn in the last section.

\section{Determinants of agricultural development in Russia}

\subsection{Evolution of Russian agriculture during the transition}

This section provides some general information on the developments in Russian agriculture since the beginning of economic reforms. Figure 1 shows the evolution of agricultural gross output and land and labour productivities. As can be seen, agricultural output declined dramatically in the early years of the transition. In 1998, the level of agricultural output was less than 60 per cent of its value in 1990. After 1998, however, total output started to increase, although annual growth was below the rate of the reduction in the previous years.

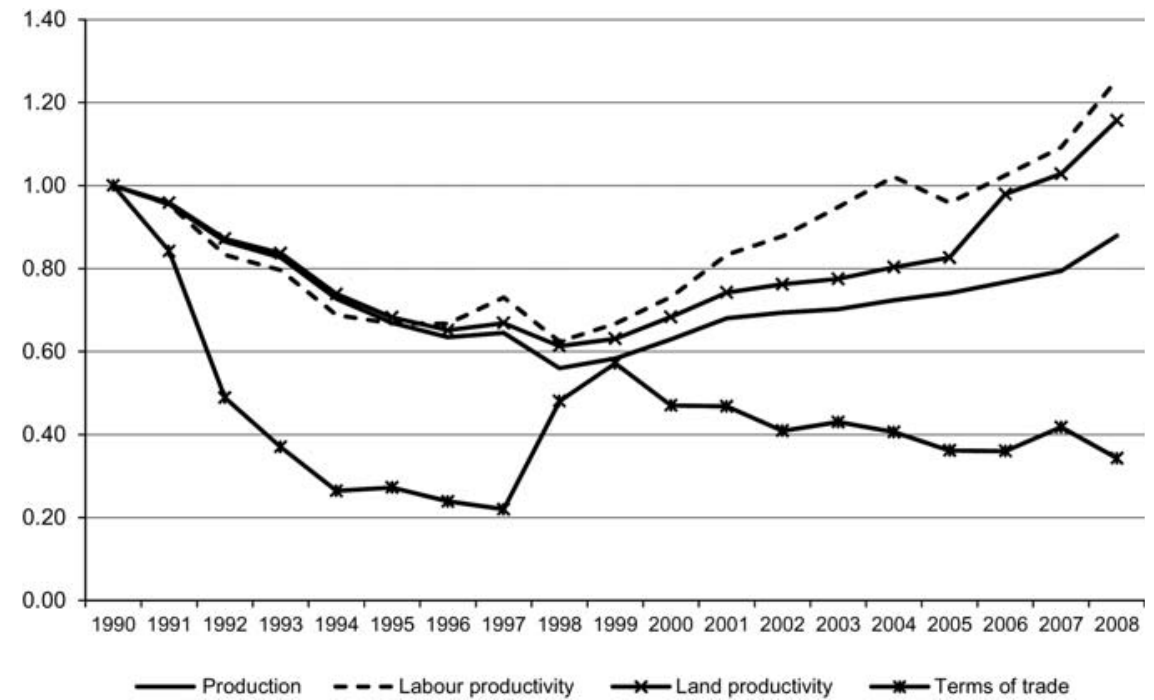

Fig. 1. Output, partial productivities and terms of trade in Russian agriculture $(1990=1)$. Source: Authors' representation based on Rosstat II (1995-2009). 
Both land and labour productivities follow the output trend, as they declined until 1998 and started to increase thereafter (Figure 1). However, while the rate of contraction for output and land and labour productivities was almost the same in the first period, both partial productivities have increased much faster than agricultural output in recent years. This fact suggests that farms have been releasing land and labour more easily in the later years of the transition. This empirical evidence highlights some important aspects of agricultural adjustments during the transition process. According to Koester (2005), a farm's persistence in keeping surplus labour can be regarded as an effect of embedded institutions from the Soviet era, when collective farms took over many of the social functions in rural areas. In addition, uncertain land regulations, as well as a belief in the comparative advantages of large-scale farming in Russia, seriously affected the evolvement of a dynamic land market, thereby hindering the disposal of excess land in the earlier years of the transition. In recent years, however, these two peculiarities of the transition process in Russian agriculture have been overwhelmed to some extent. This trend has been apparently associated with the emergence of new types of agricultural enterprises - large vertically integrated holdings (Hockmann, Bokusheva and Bezlepkina, 2009). These agroholdings have brought superior entrepreneurial and managerial skills and advanced technologies to Russian agriculture and thus have induced a more efficient resource allocation (Rylko et al., 2008).

Figure 1 suggests that the decline of output and productivity was accompanied by deteriorating TOT; i.e. the relationship between agricultural producers' output and input prices. Obviously, an over-proportional increase in input prices compared with producers' output prices induced a substantial reduction in farm output. ${ }^{2}$ However, TOT cannot be regarded as the only source of output and productivity changes. Indeed, despite a further decline in the output-input price relationship after 2001, output has been steadily increasing. This indicates that relative prices can explain the evolution of productivity in Russian agriculture only to a certain extent. Thus, one can argue that other factors, like macroeconomic conditions, the development of input markets and changes in the institutional environment, as well as access to modern technologies, may have contributed significantly to the recent developments in Russian agriculture.

Figure 2 shows that Russian farms seriously reduced the use of all factors of production during the transition. However, the reduction in factor use was uneven across different input categories, which suggests a significant effect of immense changes in relative prices on factor use by Russian farms.

Regarding variable inputs, the only data available from official statistics pertained to fertiliser. Consistent with the TOT development, the use of this input declined dramatically in the early years of the transition. However,

2 A thorough examination of the effect of deteriorating terms of trade on the agricultural output development in Russia during the transition period can be find in Liefert (2001) and Liefert and Swinnen (2002). 


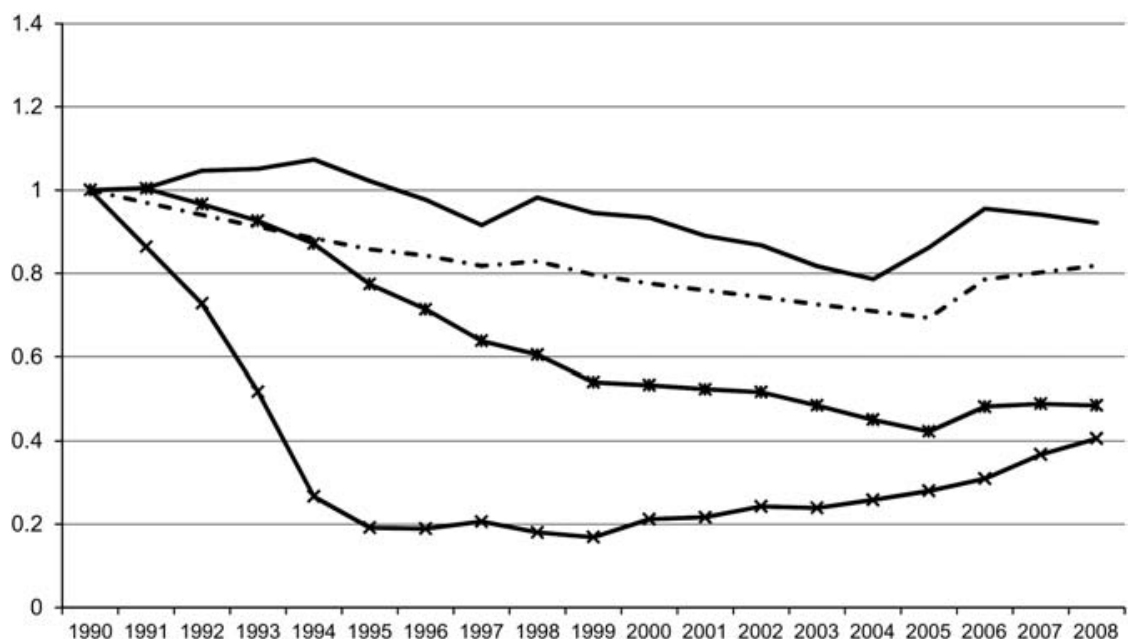

-Man-Land ratio $\quad-$ - Capital intensity $\rightarrow$ Fertilizer intensity

$\rightarrow$ Animal intensity

Fig. 2. Factor use in Russian agriculture $(1990=1)$.

Source: Authors' representation based on Rosstat II (1995-2009).

Note: All indicators are defined in relation to land input.

fertiliser use reached a turning point in the mid-1990s and started to increase steadily, despite the still deteriorating TOT. ${ }^{3}$

A large decline was also observed for animal input, which was dictated by comparative disadvantages in livestock production in Russian agriculture after market liberalisation (Liefert, 2002). Since 2006, however, the number of animals has begun to increase again. This development most probably was influenced by the governmental programme introduced in 2006 to support domestic livestock and poultry production. Although less dramatic, fixed assets in agriculture have shown a similar pattern, i.e. their use decreased until 2005 and then started to increase rapidly in recent years.

As shown in Figure 2, the decline in the man-land ratio (MLR) has not been as straightforward as that seen for other inputs: it increased in 1992, then declined until 1997 and grew again in 1998. In the six subsequent years, it decreased steadily before starting to rise again in 2005. Increases in labour intensity in 1992 and again in 1998 were apparently related to the price liberalisation reform of 1992 and the Russian financial crisis of 1998, which suggests that Russian agriculture provided a buffer for labour released from other sectors of the economy in these periods. The most recent increase in MLR most probably was connected with the rise in animal input per hectare. In general, the reduction in MLR can be considered as marginal compared with other inputs. This result is particularly surprising, considering the 
tremendous decline in animal input per hectare. The reduction in animal input per hectare should have caused a stronger release of labour input per hectare. This empirical evidence suggests that Russian farms are still strongly involved in provision of social amenities and services in rural areas.

The developments discussed above point to some peculiarities in the evolution of agricultural production and productivity in Russia. In particular, empirical evidence indicates that factor use and production patterns are governed not only by economic incentives, but also by inherited institutions. This is especially true for the use of labour. Although Russian agriculture is highly industrialised, this tendency most probably will continue, considering the size and shape of the area under cultivation. In addition, the role of animal production has declined dramatically, i.e. the data indicate an increased specialisation towards crop production. Finally, the year 1998 was obviously pivotal for Russian agriculture in terms of production and productivity growth.

\subsection{Literature review: productivity and technical efficiency evolution at the regional level}

Many studies have been conducted to analyse the development of Russian agricultural production over the last two decades. Given the size of the country, the diversity of its natural conditions and the significance of agriculture in various regions, most of these studies have taken a regional perspective. In general, they focused primarily on two leading indicators: (i) the impact of technical change (i.e. shifts of the production frontier as an indicator of sustainable growth); and (ii) changes in technical efficiency, which are regarded as adjustments towards the frontier.

Using regional data on agricultural output and inputs for 75 Russian regions from 1990 to 1995, Sotnikov (1998) found a positive effect of reforms on regional technical efficiency. Nevertheless, according to Sotnikov, progress in reducing technical inefficiency was inhomogeneous across the regions. In addition, although the author detected a substantial change in the importance of different inputs, he could not find any significant effect of technical change.

Sedik, Trueblood and Arnade (1999) also studied technical efficiency at the regional level. However, in contrast to Sotnikov's approach, these authors considered only the output from crop production. Their results indicate that technical efficiency declined from 1991 to 1995. At the same time, divergences in technical efficiency scores across regions were less pronounced than in the analysis by Sotnikov (1998).

Osborne and Trueblood (2006) also found a trend towards decreasing economic efficiency of crop production in Russian corporate farms for the period from 1993 to 1998. The same tendency was revealed by Voigt and Uvarovsky (2001) for technical efficiency and technical change in Russian regions. In addition, both studies pointed to a growing divergence in productivity development among individual regions. Nevertheless, using an extended data set for the period from 1993 to 2001, Voigt (2006) was unable to find any significant changes in the technical efficiency of agricultural production in Russian 
regions. He also pointed to a growing divergence in the development of technical efficiency across the regions. Lastly, according to this study, technical change had a positive turn in 1998 for the first time since the beginning of the transition process.

While studying the effect of budget constraints at the regional level, Arnade and Gopinath (2000) found that only six oblasts were overall efficient, whereas the rest of the oblasts experienced profit losses up to 36 per cent due to different sources of inefficiency. Similar to the findings of Sotnikov (1998), Voigt and Uvarovsky (2001) and Osborne and Trueblood (2006), this study reported a high variation in regional efficiency scores.

Summing up, although most of these studies found large differences in technical efficiency scores across regions, only limited concordance was found regarding its evolvement during the transition. The effect of technical change was either insignificant or negative for the period until 1998, although some of the more recent studies found positive technical change after 1998.

\subsection{Hypotheses}

Using farm level data, a recent study by Bokusheva and Hockmann (2006) found considerable differences not only in regional production technologies, but also in the pattern of technical efficiency development in individual regions. They argue that technical efficiency in Russia might have been affected by the speed of technical change. Their analysis demonstrates that the regions with constant technology (i.e. no technical change) showed a tendency towards increasing technical efficiency, whereas this trend was reversed in those regions with substantial technical progress. The authors argue that firms under constant technology learn from past experience and are therefore on a path towards the best production practice (catching up). However, if technical change shifts the production possibility set outwards, the distance to the best domestic practice increases for enterprises that fail to adopt the innovative production technology. The latter causes a decline in the average technical efficiency.

The findings by Bokusheva and Hockmann (2006) are relevant in two respects: first, they suggest a high heterogeneity across Russian regions; second, they indicate a simultaneity problem related to high interdependency in terms of factor use decisions, technical change and technical efficiency. Both problems can result in biased estimates of the production technology parameters. However, these problems have not been yet addressed in any analysis on Russian agricultural productivity.

Given that 1998 was a turning point with respect to many performance indicators, we assume this year to be pivotal as well for the trend in productivity development. Indeed, radical change in policies were implemented to increase macroeconomic stability and to avoid governmental solvency problems. One aspect of these adjustments by the state was a retreat from controlling the economy. In turn, market mechanisms became more effective, which facilitated sustainable economic growth (Voigt and Hockmann, 2008). 
In addition, the devaluation of the Russian Rouble enhanced the competitiveness of domestic production, thereby fostering investment activity. In fact, the years following 1998 have seen an enormous investment in Russian food processing and agriculture, primarily by agroholdings (Hockmann, Bokusheva and Bezlepkina, 2009). Accompanied by political and economic reforms, these processes supposedly have improved productivity and efficiency. Thus, we hypothesise that total factor productivity will show a U-shaped or J-shaped development, with an upward slope after 1998. At the same time, we hypothesise that technological upgrading, if occurring at different rates across regions, might cause a lag in the development of technical efficiency. Therefore, our hypothesis is that technical efficiency did not show improvement immediately after 1998, but did so later.

As discussed in Section 2, Russian agriculture still provides social functions in rural areas. Since the involvement in social services might divert farm resources from agricultural activities, regions with a higher MLR are likely to exhibit lower technical efficiency.

In addition, we argue that technical efficiency can be explained by additional factors. In particular, three main sources of inefficiency can be distinguished. The first source concerns the level of economic and social development of a region. Overall regional development can be expected to exert a positive impact on technical efficiency in agriculture. Favourable economic conditions, including a stable and well-functioning economic environment and a solid supply and demand, can be expected to find their expression in the form of regional growth, which is usually accompanied by a higher per capita income. Since these economic conditions affect all sectors, they offer good prospects for agricultural development. This suggests a positive relationship between regional per capita income and technical efficiency in agriculture.

A similar impact can be expected from social development. The social infrastructure supports people and communities in their basic needs and therefore assists them in the fulfilment of their economic function. Consequently, we hypothesise that a better-developed social infrastructure will improve technical efficiency. In the present study, we use the number of kindergarten spots per 100 children of kindergarten age as a proxy for the development of social infrastructure in a region.

The second source of inefficiency relates to the adjustment processes arising from the transition process. Even though policy makers were reluctant to introduce market-oriented reforms in the agricultural sector, the economic environment changed dramatically, as indicated by the development of the agricultural TOT (Figure 1). These changes imposed considerable adjustment costs associated with reorganisation of production and learning processes. Adjustment costs might have had a negative influence on technical efficiency, because farm resources have not been allocated solely to production, but had to be provided for initiating and implementing necessary restructuring processes. This type of an effect would be expected for regions with a higher initial level of specialisation in animal production. Indeed, Figure 2 shows that transition fostered a specialisation in crop production. Accordingly, 
regions with higher specialisation in livestock production would have higher adjustment costs (due to reallocation of resources) and would thus be less efficient.

The third source results from the limited availability of statistical information on factor quality. This primarily concerns the measurement of capital. Official statistics in Russia provide two indicators that are likely to complement the assessment of capital quality: the share of outdated capital in total capital input and the investment volume. We use the first indicator to derive a more adequate measure of the capital input. ${ }^{4}$ We use the second indicator to test whether regions with higher investment rates have lower inefficiencies.

These three sources of technical inefficiency (i.e. a region's economic and social development, adjustment costs and input quality) are not transitionspecific. Nevertheless, given the radical changes experienced by Russian farms, they might have been more distinctive and hence might have a stronger effect on technical efficiency than in well-established market economies.

\section{Model and estimation methodology}

In the panel data framework, agricultural production technology is typically specified as:

$$
\ln y_{i t}=f\left(\mathbf{x}_{i t} ; \boldsymbol{\alpha}\right)+\eta_{i}+v_{i t}-u_{i t}
$$

where $y_{i t}$ is the output by producer (region) $i$ in the period $t, \mathbf{x}_{i t}$ is a vector of inputs, $\boldsymbol{\alpha}$ is a vector of technology parameters to be estimated, $\eta_{i}$ is a vector of unobserved producer-specific effects, $u_{i t}$ is the technical inefficiency component assumed to be i.i.d. with $u_{i t} \sim \mathrm{N}^{+}\left(0, s_{u}{ }^{2}\right), v_{i t}$ is a stochastic noise component assumed to be i.i.d., with $v_{i t} \sim \mathrm{N}\left(0, s_{v}{ }^{2}\right)$ and $f\left(\mathbf{x}_{i t} ; \boldsymbol{\alpha}\right)$ represents the production frontier.

The production function defined by equation (1) is usually estimated by the ML method, which uses the above distributional assumptions on $u_{i t}$ and $v_{i t}$. The use of the ML method presupposes that unobserved heterogeneity can be adequately captured by fixed/random effects. Additionally, in this type of formulation, inputs are almost always assumed to be exogenous, especially when no behavioural assumptions are made. This means that input variables are not correlated with either inefficiency or the noise components. However, if these assumptions are violated, the use of the ML method can result in inconsistent and biased estimates of the production technology and technical inefficiency.

In this study, we assume that input and output variables are endogenous. Following Kumbhakar (2011), we specify the technology as $A_{i t} f\left(\mathbf{x}_{i t}, y_{i t}\right)=1$, where $\ln A_{i t}=\eta_{i}+v_{i t}-u_{i t}$ and assume that producers maximise returns to the outlay by choosing optimal input and output quantities 
$\left(\mathbf{x}_{i t}\right.$ and $\left.y_{i t}\right)$. Under this behavioural assumption, the production technology can be expressed as ${ }^{5}$ :

$$
\ln \left(\frac{x_{1 i t}}{y_{i t}}\right)=-g\left(\ln \hat{\mathbf{x}}_{i t} ; \boldsymbol{\alpha}\right)-\eta_{i}-v_{i t}+u_{i t},
$$

where the dependent variable is partial productivity (in log) of input $x_{1}, j$ is the production input subscript $(j \in J), \hat{\mathbf{x}}_{j i t}$ is the vector of $J-1$ other inputs normalised by the input $x_{1}$ (i.e. $\left.\hat{x}_{j i t}=x_{2 i t} / x_{1 i t}, j=2, \ldots, J\right)$. The functional form of $g($.$) can be easily derived from the functional form of f($.$) . For$ example, if $f($.$) is translog, g($.$) will also be translog [see equations (11) and$ (12) in Kumbhakar (2011)].

To test our research hypotheses (specified in Section 2.3), we employ a more general formulation to account for determinants of inefficiency and heteroskedasticity in the noise term (Kumbhakar and Lovell, 2000; Wang, 2002), viz.:

$$
\begin{gathered}
v_{i t} \sim N\left(0, \sigma_{v, i t}^{2}\right) \text { with } \sigma_{v, i t}=\exp \left(\sum_{j=1}^{J} \boldsymbol{\delta}^{\prime} \mathbf{w}_{i t}\right) \text { and } \\
u_{i t} \sim N^{+}\left(0, \sigma_{u, i t}^{2}\right) \text { with } \sigma_{u, i t}=\exp \left(\sum_{k=1}^{K} \boldsymbol{\gamma}^{\prime} \mathbf{z}_{i t}\right),
\end{gathered}
$$

where the $\mathbf{w}$ and $\mathbf{z}$ variables are regional specifics that explain heteroskedasticity (production risk) and inefficiency, respectively.

Kumbhakar (2011) argued that the regressors in equation (2) can be treated as exogenous (i.e. uncorrelated with the error components). If this is the case, then the model specified in equations (2) and (3) can be estimated using the standard SF model. However, the exogeneity condition in Kumbhakar (2011) is based on the assumption that either there are no allocative errors or allocative errors are independent of the error components in equation (2). If this assumption does not hold, then the input ratios in equation (2) will be correlated with the error components, which will render the SF model inconsistent. That is, the single-step ML method cannot be used for consistent estimation of the technology parameters. In this case, one has to use a two-step approach. In the first step, one can use a GMM estimator to obtain consistent estimates of the parameters associated with the frontier model. In the second step, the ML method can be used to estimate technical efficiency. The advantage of using the GMM estimator is that it allows possible correlation between regressors and the error components (inefficiency and noise), as well as

5 The first-order conditions of this problem show that $f\left(\right.$.) is homogeneous of degree zero in $\mathbf{x}_{i t}$ and $y_{i t}$ [see equation (6) in Kumbhakar (2011)] and therefore $A_{i t} f\left(\mathbf{x}_{i t}, y_{i t}\right)=1$ can be rewritten as in equation (2). It is worth noting that equation (2) can also be derived assuming constant returns to scale. Our estimate of returns to scale based on system GMM using equation (1) is not much different from unity. This suggests that the estimating equation (2) can also be derived without any explicit behavioural assumption. 
heteroskedasticity and autocorrelation of unknown forms. In addition, estimating the model in first differences allows for consistent estimates of the frontier in the presence of heterogeneity in the intercept.

In the present paper, similar to Guan et al. $(2009)^{6}$ we adopt a two-step approach. Since the first-differenced GMM estimator produces biased estimates in the presence of 'weak instruments' (Mairesse and Hall, 1996; Blundell and Bond, 1998), we use the system GMM estimator in the first step. Blundell and Bond (1998) have shown that the system GMM estimator is more powerful when only weak correlation exists between the current and lagged values of model variables. ${ }^{7}$

To apply the system GMM, we rewrite the expression in equation (2) in the following way:

$$
\ln \left(\frac{x_{1 i t}}{y_{i t}}\right)=E\left(u_{i t}\right)-g\left(\ln \hat{\mathbf{x}}_{i t} ; \boldsymbol{\alpha}\right)+\theta_{i t},
$$

where

$$
\theta_{i t}=-\eta_{i}-v_{i t}+\left(u_{i t}-E\left(u_{i t}\right)\right) \text {. }
$$

This reformulation makes $E\left(\theta_{i t}\right)=0$, when $\eta_{i}$ is a zero mean random variable (which is the standard for the random effects in panel data models). If region-specific effects are assumed to be fixed, they are included in the regressors [i.e. the $\eta_{i}$ values are treated as parameters and are included in the $; \boldsymbol{\alpha}) ; \boldsymbol{\alpha})$ function] and $\theta_{i t}=-v_{i t}+\left(u_{i t}-E\left(u_{i t}\right)\right)$ is a zero mean random variable. Finally, if $E\left(u_{i t}\right)$ is a constant, it will be subsumed by the intercept term in $g\left(\ln \hat{\mathbf{x}}_{i t} ; \boldsymbol{\alpha}\right)$. Thus, the formulation in equation (4a) is no different from a standard regression model in which a system GMM can be applied.

However, because of the heteroskedasticity assumption in equation (3b), $E\left(u_{i t}\right)$ depends on the $\mathbf{z}$ variables, i.e. $E\left(u_{i t}\right)=\sqrt{2 / \pi} \sigma_{u}\left(\mathbf{z}_{i t}\right)$, which is not a constant. Hence, the intercept term $E\left(u_{i t}\right)-\alpha_{0}$ becomes a function of the $\mathbf{z}_{i t}$ variables and is region-specific and time-varying. Consequently, the production technology in equation (4a) has to be rewritten as:

$$
\ln \left(\frac{x_{1 i t}}{y_{i t}}\right)=\sqrt{\frac{2}{\pi}} \sigma_{u}\left(\mathbf{z}_{i t}\right)-g\left(\ln \hat{\mathbf{x}}_{i t} ; \boldsymbol{\alpha}\right)+\theta_{i t} .
$$

Thus, the $\mathbf{z}$ variables are used as regressors in the model, along with the input variables in the first step. If these $\mathbf{z}$ variables are part of the production technology (to capture regional heterogeneity), then the relationship in equation

6 While Guan et al. (2009) uses GMM in the first stage of the two-step estimation procedure to avoid endogeneity problem, we use a system GMM which uses both level and differenced instruments.

7 Accordingly, the application of the system GMM is highly relevant in the context of highly persistent data (Blundell and Bond, 1998). This applies quite often to quasi-fixed production factors such as capital and labour. In agriculture, this is valid also for the land input. The system GMM also has been shown to be more powerful than the standard first-differenced GMM estimator when estimating a production function for a moderately short panel of data. 
(5a) can be implicitly expressed as $\ln \left(x_{1 i t} / y_{i t}\right)=m\left(\ln \hat{\mathbf{x}}_{i t}, \mathbf{z}_{i t} ; \boldsymbol{\alpha}\right)+\theta_{i t}$, where the $m$ (.) function includes both the $\mathbf{x}$ and $\mathbf{z}$ variables. In our empirical specification, we follow this general formulation and specify $m\left(\ln \hat{\mathbf{x}}_{i t}, \mathbf{z}_{i t} ; \boldsymbol{\alpha}\right)$ as a translog function, viz.:

$$
\begin{aligned}
\ln \left(\frac{x_{1 i t}}{y_{i t}}\right)= & \alpha_{0}+\alpha_{t} t+\alpha_{t t} \frac{1}{2} t^{2}+\sum_{j=2}^{J} \alpha_{j} \ln \hat{\mathbf{x}}_{j i t}+\sum_{j=2}^{J} \alpha_{j t} \ln \hat{\mathbf{x}}_{j i t} t \\
& +\frac{1}{2} \sum_{k=2}^{J} \sum_{j=2}^{J} \alpha_{j k} \ln \hat{\mathbf{x}}_{j i t} \ln \hat{\mathbf{x}}_{k i t}+\sum_{l=1}^{L} \beta_{l} \ln z_{l i t}+\sum_{l=1}^{L} \beta_{l t} \ln z_{l i t} t \\
& +\frac{1}{2} \sum_{m=1}^{M} \sum_{l=1}^{L} \beta_{l m} \ln z_{l i t} \ln z_{m i t}+\frac{1}{2} \sum_{j=2}^{J} \sum_{l=1}^{L} \phi_{j l} \ln \hat{\mathbf{x}}_{j i t} \ln z_{l i t}+\theta_{i t} .
\end{aligned}
$$

Note that we also added $t$ (a time trend variable) to the above specification. Finally, $l$ is the subscript for the $z$ variables $(l \in L)$.

In contrast to the standard GMM in differences, the system GMM estimates the model both in differences and also in levels. The GMM approach estimates the model parameters directly from the moment conditions. In particular, the system GMM estimator is based on the following conditions:

$$
\begin{aligned}
& E\left(\ln \hat{\mathbf{x}}_{j i, t-p} \Delta \theta_{i t}\right)=0 \quad \text { for } \quad p \geq 2, \\
& E\left(\Delta \ln \hat{\mathbf{x}}_{j i, t-s} \theta_{i t}\right)=0 \quad \text { for } \quad s=1,
\end{aligned}
$$

where $\hat{\mathbf{x}}_{j i, t-p}$ are the normalised input variables lagged two periods and more, $\theta_{i t}$ is the composed error term and $\Delta \theta_{i t}=\theta_{i t}-\theta_{i, t-1}$. We also added the moment conditions for the exogenous variables $\left(\mathrm{z}_{l i t}\right)$. Accordingly, two types of instruments are employed: the level instruments for the differenced equations and the lagged differences for the equations in levels (Arellano and Bover, 1995).

The moment conditions in equation (6a) allow the use of the $\hat{\mathbf{x}}$ and $\mathbf{z}$ variables lagged at least two periods as the instruments for the model estimation in first differences, i.e. it is assumed that no correlation exists between input variables lagged adequately and the error term in first differences (which eliminates the random region-specific effects). The conditions in equation (6b) describe additional moment conditions required for the system GMM estimation (Arellano and Bover, 1995). They allow the use of suitably lagged first differences of the exogenous variables as instruments for the equations in levels. ${ }^{8}$ Hence, the estimation of the model in differences eliminates regionspecific effects and the use of the lagged level instruments in the differenced equations controls for simultaneity problem, whereas the use of additional

8 The moment conditions in equations (6a) and (6b) will hold irrespective of whether regionspecific effects are fixed or random. 
instruments (i.e. lagged differences in the level equations) accounts for weak instrument problems.

The estimation of the production technology by system GMM provides consistent estimates of the technology parameters $\boldsymbol{\alpha}$ and a residuals vector $\theta_{i t}$. In the second step, we use a standard ML-based SFA model to estimate technical efficiency and its determinants. In this step, we extend the work of Wang (2002) and calculate marginal effects of inefficiency determinants on the expected technical inefficiency by considering heteroskedasticity not only in the inefficiency term, but also in the stochastic noise component. The calculation of marginal effects follows the derivations presented in Appendix A.

\section{Data}

In our analysis, we use the data from the Russian National Statistical Agency (Rosstat) for 59 of the 79 Russian regions, covering the period from 1991 to 2008. Although information is obtainable for almost all regions, our sampling intentionally excluded the regions of the Far East and Northern districts that have extremely unfavourable climatic conditions for agricultural production. Consideration of these regions in the analysis might have caused serious noise in the data, and consequently biased the estimates of the production technology.

Output is defined as regional agricultural gross production. The vector of inputs comprises land, labour, capital and variable inputs. Land is measured by the sown area. Labour is defined as the number of agricultural workers. Variable input costs are measured as the difference between agricultural gross production and gross domestic product. The fixed assets are revaluated several times during the 1990s in Russian agriculture. Nevertheless, the official statistics do not provide relevant indices for single revaluations, which complicate derivation of a reliable measure of capital. In our study, we obtain the value of capital from official statistics on the extent of capital depreciation in single years, which considers the movement of capital in successive years. Accordingly, we obtain the net value of capital (i.e. without depreciation) for a base year and derive its net values for other years, while considering the extent of capital depreciation in every single year compared with the base year level of depreciation. This allowed us to trace the capital value changes in net capital in the base year prices.

Output and variable inputs were deflated by corresponding price indices (i.e. index of agricultural producer prices and agricultural input price index) to the price level in 2000 - the base year in our analysis. ${ }^{9}$ In addition, all variables were normalised by their geometrical means. The dependent variable was defined as the ratio of variable inputs to the production output. The other three inputs were normalised by variable inputs. ${ }^{10}$

9 Summary statistics for the variables used in the model can be found in Table B1 (Appendix B in supplementary data available at ERAE online).

10 In addition, we employ a dummy variable representing main agricultural regions (MAIN). 
The variables used in $\mathbf{z}$ correspond to the hypotheses mentioned in Section 2.3. In particular, these vectors include regional per capita real income growth rate (INC), investment to capital rate (ICR), TOT, share of livestock production in the regional agricultural gross output (LCR), MLR and the number of kindergarten spots per 100 children of kindergarten age (CCC). The $\mathbf{w}$ vector includes the variables that might explain heteroskedasticity in the error (noise), i.e. production risk, and consists of ICR, TOT, LCR, MLR and CCC.

\section{Estimation results}

\subsection{Parameter estimates}

Table 1 presents estimates of the production technology parameters obtained by three approaches employed on equation (4a): the homoskedastic and heteroskedastic SFA models, based on the ML method (columns 'homoskedastic ML SF' 'heteroskedastic ML SF', respectively) and the system GMM-based approach. Note that the first two approaches do not correct for potential endogeneity, while the third one does.

To highlight possible impact of the endogeneity problem (i.e. the correlation between the input variables and the composed error term), we first compare the frontier estimates of the ML-based SFA models and the GMM approach. The parameter estimates differ considerably between these two approaches. These differences are reflected in the estimates of technical change as well as input elasticities. ${ }^{11}$ Both ML-based SFA models show a remarkable increase in technical change over time. This is likely to be an upward bias. According to the system GMM estimates, technical change decreased in the 1990s and showed much more moderate growth rates in the last decade.

In the ML estimates, materials account for about 36 per cent of the value of output. Given that the share of this factor in gross production is about 43 per cent, its estimate appears to be downward biased. In contrast, the GMM-based approach produces an estimate that is rather close to the share of materials in the gross production. The downward bias of the ML estimates for materials is compensated by an upward bias in the elasticity of labour. In addition, contrary to system GMM, the ML estimates are not theoretically consistent. Although monotonicity of the sample means holds for all inputs, the necessary condition for quasi-concavity is not satisfied for two inputs: labour and capital. Summing up, the endogeneity appears to be a problem for the ML-based estimations of the SFA model, whereas the system GMM produces consistent and more reliable results (without any distributional assumptions on the error components).

11 The system GMM model was found to be highly significant according to the Wald test with $\mathrm{Chi}^{2}(v=45)=3.46 \mathrm{e}+04$. In addition, the Sargan test could not reject validity of the instruments $\left[\chi^{2}(v=2475)=1342\right]$. Finally, the Arellano-Bond test rejected second-order autocorrelation $(\operatorname{Pr}>z=0.521$ for $z=0.64)$. 
Table 1. Production technology parameter estimates ${ }^{\mathrm{a}}$

\section{Estimate}

Variable

Homoskedastic ML SF Heteroskedastic ML SF System GMM ${ }^{\mathrm{b}}$

Inputs

$\begin{array}{lc}\text { Time } & -0.030 * * * \\ \text { Time* } & -0.003 * * * \\ \text { Time*INC } & -0.108 * * * \\ \text { Time*CCC } & 0.021 \\ \text { Time*TOT } & 0.002 \\ \text { Time*LCR } & -0.009 \\ \text { Labour } & -0.297 * * * \\ \text { Labour*Time } & -0.027 * * * \\ \text { Labour*INC } & 0.647 * * * \\ \text { Labour*CCC } & -0.133 \\ \text { Labour*TOT } & -0.128 * * \\ \text { Labour*LCR } & -0.063 \\ \text { Land } & -0.076 * * * \\ \text { Land*Time } & 0.005 \\ \text { Land*INC } & -0.009 \\ \text { Land*CCC } & -0.083 \\ \text { Land*TOT } & 0.134 * * * \\ \text { Land*LCR } & 0.034 \\ \text { Capital } & -0.250 * * * \\ \text { Capital*Time } & 0.009 \\ \text { Capital*INC } & 0.479 * * \\ \text { Capital*CCC } & -0.048 \\ \text { Capital*TOT } & 0.247 * * * \\ \text { Capital*LCR } & 0.078 \\ \text { Labour2 } & -0.624 * * * \\ \text { Land2 } & 0.041 \\ \text { Capital2 } & -0.347 * * * \\ \text { Labour*Land } & -0.219 * * * \\ \text { Labour*Capital } & 0.435 * * * \\ \text { Land*Capital } & 0.223 * * * \\ & \\ & \\ & \end{array}$

$\begin{array}{lc}-0.026^{* * *} & -0.012^{* *} \\ -0.003^{* *} & -0.005^{* * *} \\ -0.094^{* * *} & -0.064^{*} \\ 0.035^{*} & 0.021 \\ 0.000 & 0.039^{* * *} \\ -0.011 & -0.016^{*} \\ -0.257^{* * *} & -0.207^{* * *} \\ -0.034^{* * *} & -0.015 \\ 0.742^{* *} & 0.100 \\ -0.250 & 0.668^{* *} \\ -0.178^{* *} & -0.002 \\ -0.150 & -0.076 \\ -0.094^{* * *} & -0.109^{*} \\ 0.006 & 0.015^{*} \\ -0.059 & 0.404 \\ -0.081 & -0.201 \\ 0.131^{* * *} & 0.320 \\ 0.069 & 0.152 \\ -0.286^{* * *} & -0.214^{* * *} \\ 0.007 & 0.007 \\ 0.579 * * & -0.243 \\ -0.007 & -0.741^{*} \\ 0.255^{* * *} & -0.261 \\ 0.163^{*} & 0.033 \\ -0.666^{* * *} & -0.162 \\ 0.018 & -0.051 \\ -0.235 & -0.010 \\ -0.170^{* *} & -0.083 \\ 0.426^{* * *} & 0.140 \\ 0.154^{* *} & 0.189\end{array}$

Regional characteristics

$\begin{array}{lc}\text { INC } & -0.242 * * * \\ \text { CCC } & -0.277 * * * \\ \text { TOT } & 0.068 * * * \\ \text { LCR } & 0.172 * * * \\ \text { MAIN } & -0.016 \\ \text { INC2 } & 0.397 \\ \text { CCC2 } & -0.153 \\ \text { TOT2 } & 0.182 * * * \\ \text { LCR2 } & 0.012 \\ \text { INC*CCC } & 0.994 * * * \\ \text { INC*TOT } & -0.050\end{array}$

0.003
$-0.168^{* *}$
$0.145^{* * *}$
$0.197^{* * *}$
$-0.033^{*}$
0.090
-0.562
0.107
0.078
$0.740^{*}$
-0.198

$-0.316 * * *$

$-0.033$

$0.204 * * *$

0.040

$0.085 * *$

0.179

$1.134 *$

0.296

0.040

0.405

$-0.116$

(continued) 
Table 1. (continued)

Estimate

Variable

Homoskedastic ML SF Heteroskedastic ML SF System GMM

$\begin{array}{lccc}\text { INC*LCR } & -0.080 & -0.097 & 0.249 \\ \text { CCC*TOT } & 0.143 & 0.109 & -0.577 \\ \text { CCC*LCR } & 0.546 * * * & 0.579 * * * & 0.828 * * \\ \text { TOT*LCR } & 0.268 * * * & 0.261 * * * & 0.195\end{array}$

Note: $*, * *, * * *$ denote statistical significance at the 10 per cent, 5 per cent and 1 per cent level, respectively.

${ }^{a}$ The respective technical efficiency estimates can be found in Table A2 in the Appendix A (in supplementary data available at ERAE online).

${ }^{\mathrm{b}}$ The list of the GMM level instruments contains all the $\hat{\mathbf{x}}$ and $\mathbf{z}$ variables and their cross-products lagged at least 2 and maximum 12 periods. The list of the differenced instruments refers to the same variables with the lag length of 1 .

The production technology estimated by the system GMM approach has the following structure. The most important production factor is variable inputs. Land inputs contribute to the agricultural gross product by roughly 11 per cent. This appears to be quite plausible, considering that land is not a very scarce factor in Russian agriculture. Consistent with large-scale farming and a high demand for capital input, the elasticity of this input is reasonably high (0.21). However, the average labour productivity of 0.20 seems to be rather high. A high level of labour elasticity might be related to high intensity and productivity of labour input in livestock and poultry production, which have been expanding due to extensive governmental interventions in recent years. The impact of technical change varied over the period of our study. It was declining until 1998 and has shown improvement since 1999. In addition, technical change is found to be land saving. ${ }^{12}$ Considering the high level of capital depreciation and moderate investment rates in recent years, capital endowment was obviously not sufficient for cultivation of large parcels of land, which forced farms to take some parcels out of cultivation.

Figure 3 summarises the overall impact of the regional characteristics representing regional economic and institutional environment on agricultural output. ${ }^{13}$ First, our results suggest an improvement in the production conditions, on average. Although not very pronounced, there is an indication that, in the period before the 1998 crisis, agricultural production suffered from a deterioration of general production conditions. After 1998, the regional environment improved, which had a positive impact on agricultural production. Second, we found a growing dispersion of the impact of regional production conditions. This result suggests that, compared with the early years

12 The coefficient estimate for the cross-product of land and time variable is positive. Based on our formulation of production technology in equation (5) and (5a), this indicates that due to technical change the amount of land needed to produce an additional unit of output reduces.

13 The values were computed using the parameter estimates form the last block of Table 1; i.e. by using the estimates of $\beta_{1}$ and $\beta_{\mathrm{Im}}$ from equation 4(a). Since all regional characteristics were normalised, the computed values correspond to the relative impact of the institutional and economic environment in the regions. 


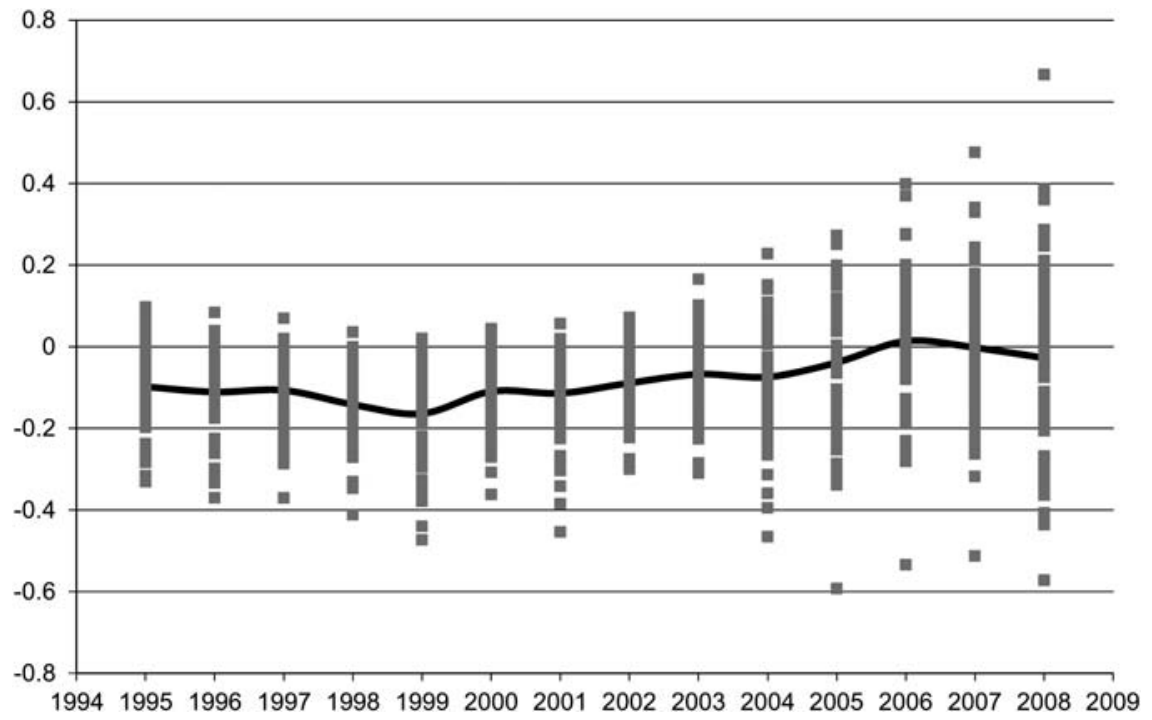

Fig. 3. Estimates of regional effects.

Note: Each dot represents one observation. The trend represents the mean in each year.

of the transition, when the production possibilities were primarily influenced by the general macroeconomic development, the effect of regional development has been more pronounced in recent years.

\subsection{Efficiency considerations}

Figure 4 depicts the technical efficiency distribution across oblasts and over time. First of all, the technical efficiency of regional agricultural production is quite high. Most of the regions were operating at more than 90 per cent efficiency. This level is higher than was found in other studies on the development of regional productivity and efficiency (e.g. Voigt, 2006; Voigt and Hockmann, 2008). ${ }^{14}$ Moreover, the high efficiency levels distinguish our results from the analyses conducted at the farm level (e.g. Bokusheva and Hockmann, 2006). Most of these studies found a relatively large variation in efficiency among farms. However, the latter does not contradict our results. Instead, it suggests that efficiency differences may be higher within the regions rather than across the regions. This result has an important policy implication: since efficiency differences are not pronounced at the regional level, federal policies aimed at increasing technical efficiency may not be a first best choice. It is rather the responsibility of the regional governments for

14 One reason for these diverse levels can be attributed to various estimation methods. Usually, the parameters are estimated by a conventional stochastic frontier model. As discussed earlier, because of the simultaneity problem, the parameter estimates, and therefore the implied efficiencies, may be biased. 


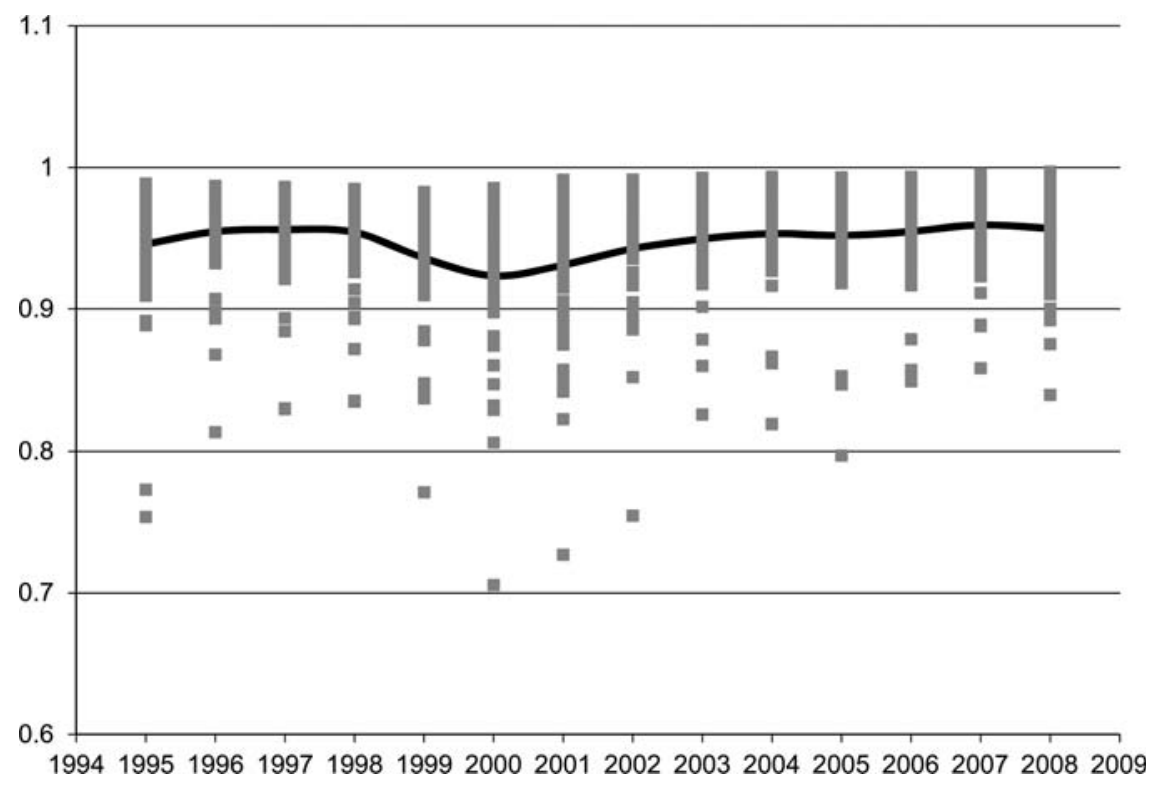

Fig. 4. Development of technical efficiency (by region and annual average).

Note: Each dot represents one observation. The trend represents the mean efficiency in each year.

developing programmes aimed at reducing production losses incurred due to inefficient use of resources at the micro level.

Figure 4 provides additional information about a general (average) trend in efficiency development. Average efficiency levels across regions declined until 2000 and then started to improve steadily thereafter. This result is in line with findings by Osborne and Trueblood (2006) and Voigt and Uvarovsky (2001), who found a decreasing pattern of technical efficiency in Russian agriculture in the 1990s. In addition, our estimates confirm the general expectations. Early years of transition were accompanied by huge uncertainties and frictions caused by institutional and economic reforms. Consequently, agricultural production was hampered and remained far below maximum potential (frontier). However, the situation has improved in recent years, which have been characterised by sustainable economic growth, macroeconomic stability and a more favourable institutional environment. Of course, it would be misleading to conclude that the reform process is now completed. Instead, policy makers should use this positive development as an argument to deepen the transition process by further reforming the institutional and organisational environments of agriculture.

Even though the data did not allow direct identification of the parameters affecting efficiency development, the estimation results provide indirect information about the sources of efficiency differences and changes. Efficiency scores were calculated using the Jondrow et al. (1982) estimator. Since 
expected inefficiency depends on the variances of $u_{i t}$ and $v_{i t}$, factors determining both variances also affect the expected technical efficiency. ${ }^{15}$ That is, we can compute the marginal effect of the $\mathbf{z}$ and $\mathbf{w}$ variables via the variances of $u$ and $v$ (if they affect both variances). In this sense, this result is different from that presented by Wang (2002). ${ }^{16}$ Table 2 presents the impact of the variables in $\mathbf{z}$ and $\mathbf{w}^{17}$ on the expected inefficiency. The results confirm that heteroskedasticity is an important phenomenon. At the same time, whereas all variables considered in the variance of $v_{i t}$ had a significant effect, only two variables, INC and TOT, were found to have significant impact on the variance of $u_{i t}$. In the following discussion, we consider only the significant effects.

Our estimates of the second step support the hypotheses introduced in Section 2.3. Technical efficiency increases with higher regional per capita income (INC), better TOT, a higher degree of social responsiveness (CCC) and a higher quality of the capital stock (INC). Moreover, a higher specialisation in animal production (LCR) and a higher MLR have negative impacts on technical efficiency. Since most of the discussed determinants are related to adjustment costs and an inappropriate measurement of the inputs, they are not transition specific. However, Table 2 also displays the effect of the MLR, which is related to the transition process. A negative impact of MLR on technical efficiency supports the hypothesis about farm involvement in the provision of social services and amenities in rural areas. Finally, the trend for average technical efficiency presented in Figure 4 suggests an increase in technical efficiency in the course of the transition. ${ }^{18}$

\subsection{TFP considerations}

Since our purpose is to discuss both TFP developments as well as TFP differences among the regions, we follow the procedure developed by Caves, Christensen and Diewert (1982). These authors derived a multilateral consistent Thörnquist-Theil index that exactly represented the changes in a translog function over time and over regions. Thus, our TFP indicator captures the differences in production technology resulting from the regional fixed effects, the changes of the frontier (technical change) and changes in technical efficiency.

Figure 5 shows a J-shaped TFP development. The early years of the transition were characterised by deterioration in production capacities. This development persisted until the Russian financial crisis in 1998. Since 1998, TFP

15 Estimates of technical efficiency determinants can be found in Table B2 (Appendix B in supplementary data available at ERAE online).

16 Essentially, this is an extension of Wang (2002), who discusses a model with heteroskedasticity only in $u$. Details are given in the Appendix A.

17 The set of $\mathbf{z}$ and $\mathbf{w}$ variables is almost identical.

18 As several $\mathbf{z}$ variables exhibited a substantial level of correlation with time variable, we do not include time as an additional variable to consider the effect of transition on technical efficiency. However, since the $\mathbf{z}$ variables such as INC, TOT and ICR incorporate effects of the transition process, their impact on technical efficiency can be regarded as an effect of the transition. 
Table 2. Heteroskedasticity and mean expected inefficiency

\begin{tabular}{|c|c|c|c|c|c|c|}
\hline \multirow[b]{2}{*}{ Variable } & \multicolumn{2}{|c|}{ Heteroskedasticity in $v$} & \multicolumn{2}{|c|}{ Heteroskedasticity in $u$} & \multirow[b]{2}{*}{$\begin{array}{l}\text { Total } \\
\text { effect on } \\
E[u \mid \varepsilon]^{\mathrm{a}}\end{array}$} & \multirow[b]{2}{*}{$\begin{array}{l}\text { Hypotheses } \\
\text { (Section 2.3) }\end{array}$} \\
\hline & $\begin{array}{l}\text { Parameter } \\
\text { estimate }\end{array}$ & $\begin{array}{l}\text { Average } \\
\text { on effect } \\
E[u \mid \varepsilon]\end{array}$ & $\begin{array}{l}\text { Parameter } \\
\text { estimate }\end{array}$ & $\begin{array}{l}\text { Average } \\
\text { on effect } \\
E[u \mid \varepsilon]\end{array}$ & & \\
\hline INC & & & $-4.844 * *$ & $<0$ & $<0$ & $<0$ \\
\hline TOT & $-0.608 * * *$ & $<0$ & $-2.545^{* *}$ & $<0$ & $<0$ & $<0$ \\
\hline LCR & $0.251 *$ & $>0$ & -2.255 & & $>0$ & $>0$ \\
\hline $\mathrm{CCC}$ & $-0.520^{*}$ & $<0$ & 1.995 & & $<0$ & $<0$ \\
\hline MLR & $0.162 *$ & $>0$ & -1.409 & & $>0$ & $>0$ \\
\hline ICR & $-0.042 * *$ & $<0$ & -0.017 & & $<0$ & $<0$ \\
\hline Cons & $-3.577 * * *$ & & $-6.887 * * *$ & & & \\
\hline \multicolumn{3}{|c|}{ Mean of $\partial E[u \mid \varepsilon] / \partial \sigma_{v}=0.008$} & \multicolumn{4}{|c|}{ Mean of $\partial E[u \mid \varepsilon] / \partial \sigma_{u}=0.738$} \\
\hline
\end{tabular}

${ }^{\mathrm{a}}$ Note: Consideration of significant parameters only.

has however increased steadily. ${ }^{19}$ One main reason behind the decline is the pronounced macroeconomic instabilities in the early years of the transition. Extremely high inflation seriously reduced producers' incentives to exploit their production possibilities. Other developments, such as a slow transition from central planning to a market economy, aggravated this effect. However, several factors also helped to improve the institutional and economic environment. Gradual progress in restructuring and in the learning process, an increased competitiveness of domestic production due to a drastic devaluation of the Russian Rouble in 1998, as well as ongoing reforms definitely induced a reversal of these deterioration processes.

We do not find evidence for s-convergence. ${ }^{20}$ On the contrary, Figure 5 demonstrates that the spread of TFP among the regions increased over the period under investigation. Moreover, the variance in TFP followed the development observed for technical efficiency and the regional characteristics: it decreased until 2000 and then started to increase. Altogether, the growing dispersion of TFP levels implies that the developments in Russian agriculture cannot be readily explained by the forces provided by neoclassical growth theory (such as diminishing marginal returns and technical change as a public good), but are strongly affected by determinants presented in "new growth theory' (Romer, 1986; Lucas, 1988). These newer models highlight the externalities between knowledge and technologies (i.e. innovations). Spill-over effects and complementarities mean that the accumulation of

19 This result confirm results by Voigt (2006) and Voigt and Hockmann (2008) who found a slight indication for an improvement in the TFP development from 1999 to 2001 and 1999 to 2003, respectively.

20 The $\sigma$-convergence refers to a situation in which single indicators for a group of countries move to a joint level (Barro and Sala-i-Martin, 1992). 


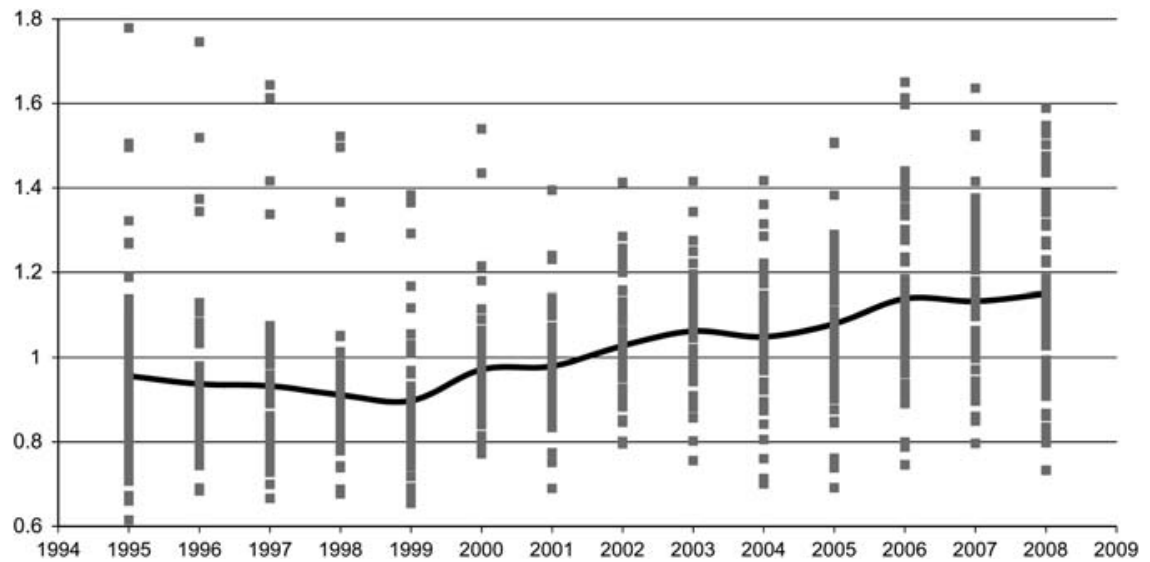

Fig. 5. TFP development (by region and annual average).

Note: Each dot represents one observation. The trend represents the mean in each year.

knowledge might be characterised by increasing returns. Furthermore, advancement of knowledge creates new complementarities between human capital and technology. Typically, the discussed mechanics induce a dispersion of TFP levels. Moreover, the transition process can be expected to enhance these divergent developments.

However, both convergence and divergence processes might be present simultaneously and hence might affect the relative position of the regions. Figure 6 indicates that this conjecture cannot be denied. The developments in most regions are characterised by $\beta$-convergence. ${ }^{21}$ Convergence processes are quite pronounced on average and amount to about 10 per cent per year. ${ }^{22}$ However, some regions, especially those with a high initial TFP level, experienced negative TFP development in the period under investigation. Basically, these regions, like all others, showed a negative TFP trend until 1998. However, in contrast to the other regions, they were unable to use the window of opportunity offered by the Russian crisis to move towards a sustainable growth path. These falling-back processes can be seen as the major reason why we were unable to observe $\sigma$-convergence.

Similar to the findings on technical efficiency, the results regarding the development of TFP suggest that policies at the federal level can be regarded only as a necessary condition for the inducing growth processes. The exploitation of growth potentials however mainly depends on how regional governments augment the incentives provided by the federal policies.

21 This kind of convergence refers to a situation where the correlation between growth rates and initial levels is negative (Barro and Sala-i-Martin, 1992). They also show that $\beta$-convergence is necessary, but not sufficient for $\sigma$-convergence.

22 Sala-i-Martin (1996) surveys the literature on $\beta$-convergence and concludes that economies close the gap between present levels of income and balanced growth levels, on average, by 2 per cent per year. 


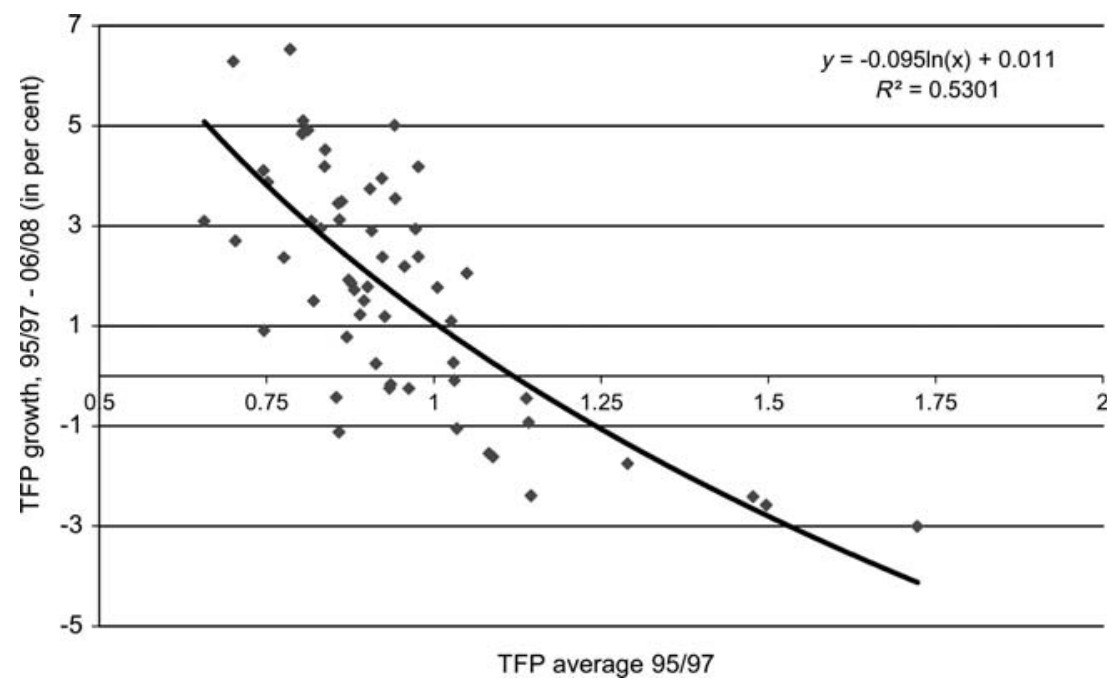

Fig. 6. Regional TFP changes and $\beta$-convergence.

Note: The parameter estimates are highly significant with t-values of about 4.3 and -8.56 for the absolute term and the slope, respectively.

\section{Conclusion and discussion}

This study used regional data on agricultural output and inputs to analyse the evolution of agricultural productivity in Russian regions during the period from 1995 to 2008. The estimation methods used in the paper take into account endogeneity of the input and output variables. The analysis applies a two-step procedure. In the first step, we use the system generalised method of moment (system GMM) approach, which gives consistent estimates of production technology parameters in the presence of endogeneity of inputs and heteroskedastic and autocorrelated errors, without making any distributional assumptions regarding the error components. In the second step, we estimate the standard stochastic frontier model to determine technical efficiency and its determinants. We then compare the results obtained by the system GMM approach with those of conventional ML estimates.

Our analysis shows that the endogeneity problem appears to be considerable in the ML estimations. We found that the system GMM gives more reliable results. This concerns the theoretical consistency of the parameter estimates, as well as the reliability of the production elasticities and the effect of technological change.

According to the system GMM estimates, the impact of technical change varied considerably over the study period. In particular, it was negative in the early years of the transition, but became positive after the Russian financial crisis in 1998. A similar trend has been found regarding technical efficiency estimates from the corresponding SF model. In particular, technical efficiency was declining at the beginning of the reforms, but has been increasing since 2001. A short time gap in the development of technical efficiency compared 
with technical change suggests that the adoption of new production technologies occurs at a different rate across Russian regions. Furthermore, we found a J-shaped TFP development, which is in line with theoretical expectations. These results suggest that economic and institutional reforms initiated during the transition have not only fostered overall economic growth, but have also been transmitted to the agricultural sector where they have stimulated the exploitation and development of production possibilities. In this context, the financial crisis of 1998 can be regarded as a turning point for the development of agricultural productivity in Russia.

In addition, our empirical results suggest that macroeconomic and institutional reforms implemented at the federal level can be considered as a necessary, but not as a sufficient, condition for agricultural development. In the early years of the transition, the effect of federal economic and institutional policies was a major driving force behind the changes in agricultural productivity, while regional policies had only a limited impact on agricultural production. However, in the period following 1998, we found quite a divergent impact of regional characteristics on production possibilities in agriculture and rather divergent developments in regional total factor productivity. This finding points to serious changes in each individual region's economic and institutional environment during the transition and a high relevance of regional policies to agricultural growth.

Finally, the second-step estimations support our hypotheses about the effect of selected regional characteristics on technical efficiency. In particular, we found that general socio-economic development of the regions, the improvement of TOT and higher investment rates had positive influences on technical efficiency. However, a higher specialisation on livestock production and a stronger involvement of farms in the fulfilment of social functions in rural areas had a negative impact on technical efficiency.

\section{Supplementary data}

Supplementary data are available at ERAE online.

\section{Acknowledgements}

The authors thank Thomas Heckelei, the editor, and two anonymous reviewers for helpful comments and suggestions. H.H. also wishes to thank Deutsche Forschungsgemeinschaft (DFG) for financial support granted under reference number HO 1302/6-1.

\section{References}

Arellano, M. and Bover, O. (1995). Another look at the instrumental variables estimation of error-components models. Journal of Econometrics 68: 29-51.

Arnade, C. and Gopinath, M. (2000). Financial constraints and output targets in Russian agricultural production. Journal of International Development 12: 71-84.

Barro, R. J. and Sala-i-Martin, X. X. (1992). Convergence. Journal of Political Economy 100: $223-251$. 
Blundell, R. and Bond, S. (1998). Initial conditions and moment restrictions in dynamic panel data models. Journal of Econometrics 87: 115-143.

Bokusheva, R. and Hockmann, H. (2006). Production risk and technical inefficiency in Russian agriculture. European Review of Agricultural Economics 33: 93-118.

Brooks, K. and Gardner, B. (2004). Russian agriculture in the transition to a market economy. Economic Development and Cultural Change 52: 571-587.

Caves, D. W., Christensen, L. R. and Diewert, W. E. (1982). Multilateral comparisons of output, input, and productivity using superlative index numbers. The Economic Journal 92: $73-86$.

Guan, Z., Kumbhakar, S. C., Myers, R. and Lansink, A. O. (2009). Measuring excess capacity in agricultural production. American Journal of Agricultural Economics 91: $765-776$.

Hockmann, H., Bokusheva, R. and Bezlepkina, I. (2009). Agroholding membership: does that make a difference in performance? Quarterly Journal of International Agriculture. 48(1): 25-46.

Jondrow, J., Lovell, C. A. K., Materov, I. S. and Schmidt, P. (1982). On the estimation of technical inefficiency in the stochastic frontier production function model. Journal of Econometrics 19: 233-238.

Koester, U. (2005). A revival of large farms in Eastern Europe: how important are institutions? Agricultural Economics 32: 103-113.

Kumbhakar, S. C. (2011). Estimation of production technology when the objective is to maximize return to the outlay. European Journal of Operational Research 208: $170-176$.

Kumbhakar, S. C. and Lovell, C. A. K. (2000). Stochastic Frontier Analysis. Cambridge: Cambridge University Press.

Liefert, W. (2001). Agricultural reform: major commodity restructuring but little institutional change. In J. Hardt (ed.), Russia's Uncertain Economic Future. Washington: U.S. Congress, Joint Economic Committee, 253-281.

Liefert, W. (2002). Comparative (dis?)advantage in Russian agriculture. American Journal of Agricultural Economics 84: 762-767.

Liefert, W. and Swinnen, J. (2002). Changes in agricultural markets in transition economies. Agricultural Economic Report No. 806. Washington: ERS, USDA.

Liefert, W., Liefert, O. and Shane, M. (2009). Russia's growing agricultural imports. causes and outlook. A Report from the Economic Research Service. Washington: United States Department of Agriculture.

Lucas, R. E. (1988). On the mechanics of economic development. Journal of Monetary Economics 22: 3-42.

Mairesse, J. and Hall, B. H. (1996). Estimating the productivity of research and development in French and US manufacturing firms: an exploration of simultaneity issues with GMM Methods. In K. Wagner and B. Van Ark (eds), International Productivity Differences and Their Explanations. Amsterdam: Elsevier Science, 285-315.

Osborne, S. and Trueblood, M. A. (2006). An examination of economic efficiency of Russian crop output in the reform period. Agricultural Economics 34: 25-38.

Romer, P. M. (1986). Increasing returns and long-run growth. Journal of Political Economy 94: 1002-1037. 
Rosstat I (annual editions from 1995 to 2010). Regiony Rossii. Statistical Yearbook of Russian Federation. Moscow (Russia): Russian statistical agency (Rosstat).

Rosstat II (annual editions from 1995 to 2009). Regiony Rossii. Statistical Yearbook: Russian Regions. Moscow (Russia): Russian statistical agency (Rosstat).

Rosstat III (annual editions from 1995 to 2009). Selskoe hozjajstvo Rossii. Statistical Yearbook: Agriculture in Russia. Moscow (Russia): Russian statistical agency (Rosstat).

Rylko, D., Khramova, I., Uzun, V. and Jolly, R. (2008). Agroholdings: Russia's new agricultural operators. In Z. Lerman (ed.), Russia's Agriculture in Transition: Factor Markets and Constraints on Growth. Lanham, MD: Lexington Books, 2008, 95-133.

Sala-i-Martin, X. X. (1996). Regional cohesion: evidence and theories of regional growth and Convergence. European Economic Review 40: 1325-1352.

Sedik, D., Trueblood, M. and Arnade, C. (1999). Corporate farm performance in Russia, 1991-95: an efficiency analysis. Journal of Comparative Economics 27: 514-533.

Sotnikov, S. (1998). Evaluating the effects of price and trade liberalisation on the technical efficiency of agricultural production in a transition economy: the case of Russia. European Review of Agricultural Economics 25: 412-431.

Voigt, P. (2006). Russia's way from planning toward market: a success story? A review of economic trajectories, transition progress and Putin's Merits. Post-Communist Economies 18(2): 123-138.

Voigt, P. and Hockmann, H. (2008). Russia's transition process in the light of a rising economy: economic trajectories in Russia's industry and agriculture. The European Journal of Comparative Economics 5(2): 251-267.

Voigt, P. and Uvarovsky, V. (2001). Developments in productivity and efficiency in Russia's agriculture: the transition period. Quarterly Journal of International Agriculture 40: 45-66.

Wang, H. J. (2002). Heteroskedasticity and non-monotonic efficiency effects of a stochastic frontier model. Journal of Productivity Analysis 18: 241-253.

\section{Appendix A: Calculation of marginal effects}

Technical inefficiency is calculated using the estimator by Jondrow et al. (1982):

$$
\begin{array}{r}
E\left[u_{i t} \mid \varepsilon_{i t}\right]=\frac{\sigma_{i t} \lambda_{i t}}{1+\lambda_{i t}^{2}}\left[\frac{\varphi\left(\zeta_{i t}\right)}{1-\Phi\left(\zeta_{i t}\right)}-\zeta_{i t}\right] \\
\text { with, } \sigma_{i t}=\sqrt{\sigma_{u, i t}^{2}+\sigma_{v, i t}^{2}} \lambda_{i t}=\frac{\sigma_{u, i t}}{\sigma_{v, i t}},
\end{array}
$$

where

$$
\begin{gathered}
\sigma_{u, i t}^{2}=\exp \left(\boldsymbol{\gamma}^{\prime} \mathbf{z}_{i t}\right), \\
\sigma_{v, i t}^{2}=\exp \left(\boldsymbol{\delta}^{\prime} \mathbf{z}_{i t}\right) \text { and } \\
\zeta_{i t}=\frac{\varepsilon_{i t} \lambda_{i t}}{\sigma_{i t}} \quad \text { and } \quad \varepsilon_{i t}=v_{i t}-u_{i t} .
\end{gathered}
$$


Given these relationships, the variables controlling for heteroskedasticity do not directly influence the expected efficiency, however, they affect it through their effect on the variances. We will demonstrate this for a variable $\eta_{\mathrm{it}}$ which is the element of both $\mathbf{z}_{i t}$ and $\mathbf{w}_{i t}$. The impact of $\eta$ on $E\left[u_{\mathrm{it}} \mid \varepsilon_{\mathrm{it}}\right]$ is given by:

$$
\frac{\partial E\left[u_{i t} \mid \varepsilon_{i t}\right]}{\partial \eta_{i t}}=\frac{\partial E\left[u_{i t} \mid \varepsilon_{i t}\right]}{\partial \sigma_{u}} \frac{\partial \sigma_{u}}{\partial \eta_{i t}}+\frac{\partial E\left[u_{i t} \mid \varepsilon_{i t}\right]}{\partial \sigma_{v}} \frac{\partial \sigma_{v}}{\partial \eta_{i t}} .
$$

The effect is not unambiguous, as demonstrated in the following. First, we rewrite equation (A1) as (subscripts omitted):

$$
\begin{gathered}
E\left[u_{i t} \mid \varepsilon_{i t}\right]=\frac{\sigma_{i t} \lambda_{i t}}{1+\lambda_{i t}^{2}}, \\
E[u \mid \varepsilon]=\phi(q)[\kappa(\zeta)-\zeta] \quad \text { with } \quad q=\frac{\sigma \lambda}{1+\lambda^{2}}>0 \quad \text { and } \\
\kappa(\zeta)=\frac{\varphi(\zeta)}{1-\Phi\left(\zeta \zeta_{i t}\right)}>0 .
\end{gathered}
$$

The partial differential, with regard to $\sigma_{u}$, is given by:

$$
\begin{gathered}
\frac{\partial E[u \mid \varepsilon]}{\partial \sigma_{u}}=\kappa(\zeta) \frac{\partial \phi(q)}{\partial q} \frac{\partial q}{\partial \sigma_{u}}+\phi(q)\left(\frac{\partial \kappa(\zeta)}{\partial \zeta}-1\right) \frac{\partial \zeta}{\partial \sigma_{u}}, \\
\text { with } \kappa(\zeta) \frac{\partial \phi(q)}{\partial q_{u}}=\kappa(\zeta)>0 \text { and } \frac{\partial q}{\partial \sigma_{u}}=\frac{\sigma_{v}^{3}}{\left(\sigma_{u}^{2}+\sigma_{v}^{2}\right)^{3 / 2}}>0 \\
\phi(q)\left(\frac{\partial \kappa(\zeta)}{\partial \zeta}-1\right)=\phi(q)\left(-1+\kappa(\zeta) \frac{E[u \mid \varepsilon]}{\phi(q)}\right)<0 \text { and } \\
\frac{\partial \zeta}{\partial \sigma_{u}}=\varepsilon \frac{\sigma_{v}^{2}}{\left(\sigma_{u}^{2}+\sigma_{v}^{2}\right)^{3 / 2}},
\end{gathered}
$$

the sign of which depends on the sign of $\varepsilon$.

Similarly:

$$
\begin{gathered}
\frac{\partial E[u \mid \varepsilon]}{\partial \sigma_{v}}=\kappa(\zeta) \frac{\partial \phi(q)}{\partial q} \frac{\partial q}{\partial \sigma_{v}}+\phi(q) \frac{\partial \kappa(\zeta)}{\partial \zeta} \frac{\partial \zeta}{\partial \sigma_{v}} \\
\text { with } \frac{\partial q}{\partial \sigma_{v}}=\frac{\sigma_{v}^{3}}{\left(\sigma_{u}^{2}+\sigma_{v}^{2}\right)^{3 / 2}}>0 \text { and } \\
\frac{\partial \zeta}{\partial \sigma_{u}}=-\varepsilon \frac{\sigma_{u}\left(2+\lambda^{2}\right)}{\left(\sigma_{u}^{2}+\sigma_{v}^{2}\right)^{3 / 2}},
\end{gathered}
$$

the sign of which corresponds to the reverse of the sign of $\varepsilon$.

The above derivatives show that the signs of $\partial E[u \mid \varepsilon] / \partial \sigma_{u}$ and $\partial E[u \mid \varepsilon] / \partial \sigma_{v}$ depend on, among other things, the sign of the composed error term 
$\varepsilon=v-u$. Furthermore, these marginal effects are observation specific. The mean impact of an explanatory variable (explaining heteroskedasticity) on the mean inefficiency can be obtained by using the arithmetic means of $\partial E[u \mid \varepsilon] / \partial \sigma_{v}$ and $\partial E[u \mid \varepsilon] / \partial \sigma_{u}$ as weights for $\sigma_{v} / \partial \eta_{i t}$ and $\sigma_{u} / \partial \eta_{i t}$ in equation (A2). 